\title{
Some Types of Irregular Labeling of Diamond Networks on Ten Vertices
}

\author{
Ali Ahmad ${ }^{1}$, Nurdin Hinding ${ }^{2}$, Jusmawati Massalesse ${ }^{2}$
}

\begin{abstract}
There are three interesting parameters in irregular networks based on total labelling, i.e. the total vertex irregularity strength, the total edge irregularity strength, and the total irregularity strength of a graph. Besides that, there is a parameter based on edge labelling, i.e., the irregular labelling. In this paper, we determined the four parameters for diamond graph on eight vertices.
\end{abstract}

Keywords: Diamond graph, irregular labeling, network

\section{INTRODUCTION}

Many types of labelling graphs that appeared after Sedlàček introduced concept labelling graphs in 1963 [12]. One of all is irregular labelling introduced by Chartrand, et al. in 1988 [4]. Let $G$ be a simple graph. A function $\gamma: E \rightarrow\{1,2,3, \ldots, b\}$ is referred to as an edge irregular b-labelling if all vertices of $G$ have vary weights. The weight of vertex $\mathrm{u}$ is $\sum \gamma(\mathrm{e})$ for an edge e incident to $u$. The irregularity strength of $G$, given a symbol $s(G)$, is the minimum positive integer $b$ so that $G$ has an irregular $b$ - labeling.

Related to the irregularity strength of some graph, Nurdin, et al. decided the irregularity strength of caterpillar graph [10]. Aigner and Triesch found that $s(G) \leq n-1$ for the number of vertices of $G$ (different from a triangle) is $n$ [2]. In fact Faudree and Lehel proved that $[\mathrm{n}+\mathrm{d}-$ $1) / d\rceil \leq s(G) \leq\left\lceil\frac{n}{2}\right\rceil+9$ for $G$ is $d-$ regular $(d \geq 2)$ graph on $n$ vertices [5].

Motivated by the notion of irregular labeling and the total labeling, Bača, et al. [3] presented the total vertex irregular labeling and the total edge irregular labeling of graphs. A function $\beta: \mathrm{V} \cup \mathrm{E} \rightarrow\{1,2,3, \ldots, \mathrm{n}\}$ is referred an edge irregular total $n$-labeling if, the weight for all edges are different. The weight of edge uv under the total labeling $\beta$ is $\beta(u)+\beta(u v)+\beta(v)$. The total edge irregularity strength of $\mathrm{G}$, denoted by tes $(\mathrm{G})$, is the minimum positive integer $n$ so that $\mathrm{G}$ has a total edge irregular $n$-labeling.

Related to the total edge irregularity strength of some graph, Bača, et al. [3] determined the total edge irregularity strength of certain classes of simple graphs, such as paths, cycles, stars, and

${ }^{I}$ College of Computer Sciences and Information Technology Jazan University,Saudi Arabia

${ }^{2,3}$ Department of Mathematics Faculty of Mathematics and Natural Sciences Universitas Hasanuddin, Makassar-Indonesia

Email address:12ahmadsms@gmail.com, ${ }^{2}$ nurdin1701@gmail.com, ${ }^{3}$ jusmawati@gmail.com

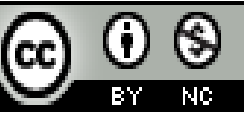

This work is licensed under a Creative Commons Attribution-NonCommercial 4.0 International License 


\section{Jurnal Matematika, Statistika \& Komputasi}

\section{Ali Ahmad, Nurdin Hinding, Jusmawati Massalesse}

wheels. The total edge irregularity strength of any graphs constructed from stars found by Nurdin and H.K. Kim [9].

Besides the total edge irregular labeling, Bača, et al. [3] also introduced the total vertex irregular labeling. For $G$ is a simple graph, a function $\mu: V \cup E \rightarrow\{1,2,3, \ldots, m\}$ is referred a vertex irregular total $m$-labeling if, the weight of all vertices are different. The weight of vertex $u$ is $\mu(\mathrm{u})+\sum \mu(\mathrm{e})$ for an edge e is edge incident to $\mathrm{u}$. The total vertex irregularity strength of $\mathrm{G}$, indicated by $\operatorname{tvs}(\mathrm{G})$, is the minimum natural number $m$ such that $\mathrm{G}$ has a total vertex irregular $m$ labeling.

Related to the total vertex irregularity strengths for various classes of graphs have been decided. For instance, Wijaya and Slamin determined the total vertex irregularity strength of friendship, fans, suns, and wheels graphs [15]. In 2013, Siddiqui, et. al. decided the total vertex irregularity strength of dijoint union of helm graph [14]. Ahmad, et al. decided the total edge and vertex irregularity strength of generalized Halin graphs [1].

In 2013, Marzuki, Salman, and Miller presented the totally irregular total on a simple graph G. A function $\theta: V \cup E \rightarrow\{1,2,3, \ldots, t\}$ is referred a totally irregular total $t$-labeling if the weight of all edges and the weight of each vertex are different. The total irregularity strength of $G$, indicated by $\operatorname{ts}(G)$, is the minimum natural number $t$ so that $G$ has totally irregular total $t$-labeling [7].

Associated with the total irregularity strength, Salman and Ramdani provide the total irregularity strength of the Cartesian product of $\mathrm{P}_{2}$ and a cycle, a star, a fan, and a path graph [11]. Marzuki, et al. decided total irregularity strength of cycle and path [7].

\section{Diamond Graph}

A diamond graph is constructed from ladder graph as define below.

Definition 1. [6] A ladder graph $L_{n}$ for $n \geq 2$ is a connected graph of order $2 n$, constructed from $P_{2} \times P_{n}$ with the vertex set

and the edge set

$$
V\left(L_{n}\right)=\left\{u_{i}, v_{i}: 1 \leq i \leq n\right\}
$$

$$
E\left(L_{n}\right)=\left\{u_{i} u_{i+1}, v_{i} v_{i+1}: 1 \leq i \leq n-1\right\} \cup\left\{u_{i} v_{i}: 1 \leq i \leq n\right\}
$$

Definition 2. [14] Let $L_{n}$ be a ladder graph as defined in Definition 1. A triangular ladder graph $T L_{n}$ for $n \geq 2$ is a connected graph of order $2 n$, constructed from $L_{n}$ by adding the edge $u_{i} v_{i+1}$ for $1 \leq i \leq n-1$. A triangular ladder graph of order $2 n-1$ can be obtained by removing $a$ vertex of degree 2 of $T L_{n}$ of order $2 n$.

Definition 3. [6] A diamond graph, denoted by $B r_{n}$, with $n \geq 2$, is a connected graph of order $2 n$, constructed from the triangular ladder graph $T L_{n}$ of order $2 n-1$ by adding a vertex $x$ and $n$ edges such that $x$ and $v_{i}$ (in Definition 1.) are adjacent.

The vertex set of $\mathrm{Br}_{\mathrm{n}}$ is

$$
V\left(B r_{n}\right)=\{x\} \cup\left\{v_{i} \mid i=1,2, \ldots, n\right\} \cup\left\{u_{i} \mid i=1,2, \ldots, n-1\right\}
$$

and the edge set of $\mathrm{Br}_{\mathrm{n}}$ is

$$
\begin{array}{r}
E\left(B r_{n}\right)=\left\{x v_{i} \mid i=1,2, \ldots, n\right\} \cup\left\{v_{i} v_{i+1} \mid i=1,2, \ldots, n-1\right\} \\
\cup\left\{u_{i} u_{i+1} \mid i=1,2, \ldots, n-2\right\} \cup\left\{u_{i} v_{i} \mid i=1,2, \ldots, n-1\right\}
\end{array}
$$




\section{Jurnal Matematika, Statistika \& Komputasi}

\section{Ali Ahmad, Nurdin Hinding, Jusmawati Massalesse}

$$
U\left\{u_{i} v_{i+1} \mid i=1,2, \ldots, n-1\right\} .
$$

An illustration of Definition 3 is shown in Figure 1.

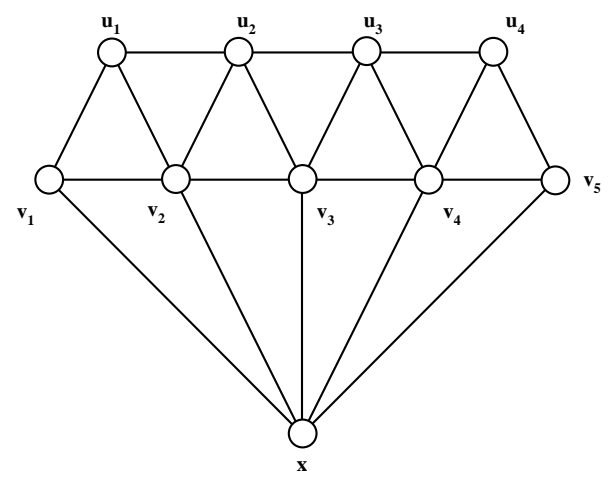

Figure 1. A Diamond Graph $B r_{5}$

\section{MAIN RESULTS}

\section{The Irregular Labeling of Diamond Graph} follows.

In this subsection, we give the found the irregularity strength of diamond graph $\mathrm{Br}_{5}$ as

Theorem 1. The irregularity strength of diamond graph $B r_{5}$ is 3.

Proof. Note that the number edges of $\mathrm{Br}_{5}$ is 20 , the sequences of degree of vertices are 3,4 , and 5. Since the weight of a vertex is the sum of label of every edges incident to the vertex, the largest weight a vertex of $\mathrm{Br}_{5}$ more than 13. Such that, $s\left(\mathrm{Br}_{5}\right) \geq \max \left\{\left\lceil\frac{13}{3}\right\rceil,\left\lceil\frac{13}{4}\right\rceil,\left\lceil\frac{13}{5}\right\rceil\right\}=3$. To prove $\mathrm{s}\left(\mathrm{Br}_{5}\right) \leq 3$, we have to construct an irregular 3-labeling of diamond graph $\mathrm{Br}_{5}$ as follows. Define an edge labelling $\gamma$ on $\mathrm{Br}_{5}$ as follows:

$$
\begin{aligned}
& \gamma\left(\mathrm{xv}_{\mathrm{i}}\right)= \begin{cases}1 & \text { for } \mathrm{i}=1,5 \\
2 & \text { for } \mathrm{i}=2,4 \\
3 & \text { for } \mathrm{i}=3\end{cases} \\
& \gamma\left(v_{i} v_{i+1}\right)= \begin{cases}1 & \text { for } i=1 \\
3 & \text { for } i=2,3 \\
2 & \text { for } i=4\end{cases} \\
& \gamma\left(v_{i} u_{j}\right)= \begin{cases}1 & \text { for }(i, j)=(1,1),(5,4) \\
2 & \text { for }(i, j)=(2,1),(2,2),(3,2),(3,3),(4,3),(4,4),\end{cases} \\
& \gamma\left(u_{i} u_{i+1}\right)= \begin{cases}2 & \text { for } \mathrm{i}=1 \\
1 & \text { for } \mathrm{i}=2 \\
3 & \text { for } \mathrm{i}=3\end{cases}
\end{aligned}
$$




\section{Jurnal Matematika, Statistika \& Komputasi}

\section{Ali Ahmad, Nurdin Hinding, Jusmawati Massalesse}

By this definition we can find that the weight of all vertices are different and $\gamma$ is defining a function $\gamma: \mathrm{E} \rightarrow\{1,2,3\}$. Such that, $\gamma$ is defining an irregular 3 -labeling of $\mathrm{Br}_{5}$. So that, $\mathrm{s}\left(\mathrm{Br}_{5}\right) \leq 3$

\section{The Total Vertex Irregular Labeling of Diamond Graph}

Nurdin, et al. provide the lower bound of the total vertex irregularity strength of any graph as in Theorem 2.

Theorem 2. [8] Let $G$ be a graph have $n_{i}$ vertices of degree $i$ for $i=\delta, \delta+1, \delta+2, \cdots, \Delta$ with $\delta$ and $\Delta$ are smallest and biggest degree of $G$, respectively. Then

$$
\operatorname{tvs}(G) \geq \max \left\{\left\lceil\frac{\delta+\mathrm{n}_{\delta}}{\delta+1}\right\rceil,\left\lceil\frac{\delta+\mathrm{n}_{\delta}+\mathrm{n}_{\delta+1}}{\delta+2}\right\rceil, \cdots,\left\lceil\frac{\delta+\sum_{\mathrm{i}=\delta}^{\Delta} \mathrm{n}_{\mathrm{i}}}{\Delta+1}\right\rceil\right\}
$$

Besides that, Bača, et al provide the lower and upper bound of the total vertex irregularity strength of any graph, as follows

Theorem 3. [3] Let $G$ be a $(p, q)$ graph with smallest degree $\delta$ and biggest degree $\Delta$, then $\left\lceil\frac{p+\delta}{\Delta+1}\right\rceil \leq \operatorname{tvs}(G) \leq p+\Delta-2 \delta+1$.

In Theorem 4, we give the value exact of the total vertex irregularity strength of diamond graph $\mathrm{Br}_{5}$.

Theorem 4. The total vertex irregularity strength of diamond graph $\mathrm{Br}_{5}$ is 3 .

Proof. Since the number vertices of degree 3 of $\mathrm{Br}_{5}$ is 4 , the number vertices of degree 4 is 2 , and the number vertices of degree five is 4 , according to Theorem 1 or Theorem 2 , we found that the total vertex irregularity strength of diamond graph $\mathrm{Br}_{5}$ bigger or equal to $\max \left\{\left[\frac{7}{4}\right\rceil,\left[\frac{9}{5}\right],\left\lceil\frac{13}{6}\right]\right\}=3$. To find the upper bound of the total vertex irregularity strength of diamond graph $\mathrm{Br}_{5}$ we have to construct a total vertex irregular 3-labeling of diamond graph $\mathrm{Br}_{5}$ as follows. Define a total labelling $\mu$ on $\mathrm{Br}_{5}$ as follows:

$$
\begin{gathered}
\mu\left(\mathrm{xv}_{\mathrm{i}}\right)= \begin{cases}2 & \text { for } \mathrm{i}=1,3 \\
1 & \text { for } \mathrm{i}=2,5 \\
3 & \text { for } \mathrm{i}=4,\end{cases} \\
\mu\left(v_{\mathrm{i}} \mathrm{v}_{\mathrm{i}+1}\right)= \begin{cases}3 & \text { for } \mathrm{i}=1,3 \\
2 & \text { for } \mathrm{i}=2,4,\end{cases} \\
\mu\left(\mathrm{v}_{\mathrm{i}} \mathrm{u}_{\mathrm{j}}\right)= \begin{cases}2 & \text { for }(i, j)=(1,1),(2,1),(3,2),(3,3) \\
1 & \text { for }(i, j)=(2,2),(4,3),(4,4),(5,4),\end{cases} \\
\mu\left(u_{i} u_{i+1}\right)= \begin{cases}2 & \text { for } i=1 \\
1 & \text { for } \mathrm{i}=2,3,\end{cases} \\
\mu(\mathrm{x})=1,
\end{gathered}
$$




\section{Jurnal Matematika, Statistika \& Komputasi}

\section{Ali Ahmad, Nurdin Hinding, Jusmawati Massalesse}

$$
\begin{aligned}
& \mu\left(v_{i}\right)= \begin{cases}2 & \text { for } 1 \leq i \leq 4 \\
1 & \text { for } i=5\end{cases} \\
& \mu\left(u_{i}\right)= \begin{cases}2 & \text { for } i=1 \\
1 & \text { for } 2 \leq i \leq 4 .\end{cases}
\end{aligned}
$$

By this definition we can find that the weight of all vertices are distinct and $\mu$ is defining a function $\mu: \mathrm{V} \cup \mathrm{E} \rightarrow\{1,2,3\}$. Such that, $\mu$ is defining a total vertex irregular 3 -labeling $\mathrm{of} \mathrm{Br}_{5}$. So that, $\operatorname{tvs}\left(\mathrm{Br}_{5}\right) \leq 3$.

\section{The Total Edge Irregularity Strength of Diamond Graphs $\mathrm{Br}_{5}$}

In 2007, Bača et al. gave the lower bound of the total edge irregularity strength of any graph as follows.

Theorem 5. [3] Let $G=(V, E)$ be graph with maximum degree $\Delta$, then

$$
\operatorname{tes}(G) \geq \max \left\{\left\lceil\frac{|E|+2}{3}\right\rceil,\left\lceil\frac{\Delta+1}{2}\right\rceil\right\}
$$

where $|E|$ is the number of edges of $G$.

In Theorem 6, we determined the total edge irregularity strength of diamond graph on 10 vertices.

Theorem 6. The total edge irregularity strength of diamond graph $\mathrm{Br}_{5}$ is 8 .

Proof. Since the number of edges of $\mathrm{Br}_{5}$ is 20 and the maximum degree of $\mathrm{Br}_{5}$ is 5 , according to Theorem 4, we found that the total edge irregularity strength of diamond graph $\mathrm{Br}_{5}$ bigger or equal to $\max \left\{\left[\frac{22}{3}\right],\left[\frac{6}{2}\right]\right\}=8$. To find the upper bound of the total edge irregularity strength of diamond graph $\mathrm{Br}_{5}$ we have to construct a total edge irregular 8-labeling of diamond graph $\mathrm{Br}_{5}$ as follows. Define a total labelling $\beta$ on $\mathrm{Br}_{5}$ as follows:

$$
\begin{gathered}
\beta\left(x_{i}\right)=8 \text { for } 1 \leq i \leq 5, \\
\beta\left(v_{i} v_{i+1}\right)= \begin{cases}2 & \text { for } i=1,2 \\
3 & \text { for } i=3 \\
6 & \text { for } i=4,\end{cases} \\
\beta\left(v_{i} u_{j}\right)= \begin{cases}1 & \text { for }(i, j)=(1,1),(2,1) \\
2 & \text { for }(i, j)=(2,2),(3,3) \\
3 & \text { for }(i, j)=(3,2),(4,3) \\
5 & \text { for }(i, j)=(4,4),(5,4),\end{cases} \\
\beta\left(u_{i} u_{i+1}\right)= \begin{cases}1 & \text { for } i=1 \\
4 & \text { for } i=2,3,\end{cases} \\
\beta(x)=8,
\end{gathered}
$$




\section{Jumal Matematika, Statistika \& Komputasi}

\section{Ali Ahmad, Nurdin Hinding, Jusmawati Massalesse}

$$
\begin{gathered}
\beta\left(v_{i}\right)=i+1 \text { for } 1 \leq i \leq 5, \\
\beta\left(u_{i}\right)= \begin{cases}1 & \text { for } i=1,2 \\
5 & \text { for } i=3,4 .\end{cases}
\end{gathered}
$$

By this definition we can find that the weight of all edges are distinct and $\beta$ is defining a function $\beta: \mathrm{V} \cup \mathrm{E} \rightarrow\{1,2, \cdots, 8\}$. Such that, $\beta$ is defining a total edge irregular 8 -labeling of $\mathrm{Br}_{5}$. So that, tes $\left(\mathrm{Br}_{5}\right) \leq 8$.

\section{The Total Irregularity Strength of Diamond Graphs $B r_{5}$}

In 2013, Marzuki, Salman, and Miller gave the lower bound of the total irregularity strength of $\mathrm{G}$ as follows.

Theorem 7. [7] Let $G$ be graph, then $\operatorname{ts}(G) \geq \max \{\operatorname{tvs}(G)$, tes $(G)\}$.

Theorem 8. The total irregularity strength of diamond graph $\mathrm{Br}_{5}$ is 8 .

Proof. Since the total vertex irregularity strength of diamond graphs and the total edge irregularity strength of diamond graphs $\mathrm{Br}_{5}$ are 3 and 8, respectively, according to Theorem 7, we prove that the total irregularity strength of diamond graph $\mathrm{Br}_{5}$ bigger or equal to 8 . To find the total irregularity strength of diamond graph $\mathrm{Br}_{5}$ smaller or equal to 8 , we have to construct a totally irregular total 8-labeling of diamond graph $\mathrm{Br}_{5}$ as follows. Define a total labelling $\theta$ on $\mathrm{Br}_{5}$ as follows:

$$
\begin{gathered}
\theta\left(\mathrm{xv}_{\mathrm{i}}\right)= \begin{cases}8 & \text { for } \mathrm{i}=1,2,3,5 \\
7 & \text { for } \mathrm{i}=4,\end{cases} \\
\theta\left(v_{\mathrm{i}} \mathrm{v}_{\mathrm{i}+1}\right)= \begin{cases}2 & \text { for } \mathrm{i}=1,3 \\
3 & \text { for } \mathrm{i}=2 \\
5 & \text { for } \mathrm{i}=4,\end{cases} \\
\theta\left(\mathrm{v}_{\mathrm{i}} \mathrm{u}_{\mathrm{j}}\right)= \begin{cases}1 & \text { for }(\mathrm{i}, \mathrm{j})=(1,1),(2,1) \\
2 & \text { for }(\mathrm{i}, \mathrm{j})=(2,2),(3,3),(4,3) \\
3 & \text { for }(\mathrm{i}, \mathrm{j})=(3,2) \\
5 & \text { for }(\mathrm{i}, \mathrm{j})=(4,4) \\
4 & \text { for }(\mathrm{i}, \mathrm{j})=(5,4),\end{cases} \\
\theta\left(\mathrm{u}_{\mathrm{i}} \mathrm{u}_{\mathrm{i}+1}\right)= \begin{cases}1 & \text { for } \mathrm{i}=1 \\
3 & \text { for } \mathrm{i}=2 \\
4 & \text { for } \mathrm{i}=3,\end{cases} \\
\theta(\mathrm{x})=8,
\end{gathered}
$$




\section{Jurnal Matematika, Statistika \& Komputasi}

\section{Ali Ahmad, Nurdin Hinding, Jusmawati Massalesse}

$$
\theta\left(u_{i}\right)= \begin{cases}1 & \text { for } i=1,2 \\ 5 & \text { for } i=3,4\end{cases}
$$

By this definition we can find that the weights of every edges are different and the weights of all vertices are distinct. Besides that, the total labelling $\theta$ is defining a function $\theta: \mathrm{V} \cup \mathrm{E} \rightarrow$ $\{1,2, \cdots, 8\}$. Such that, function $\theta$ is defining a totally irregular total 8 -labeling of $\mathrm{Br}_{5}$. So that, ts $\left(\mathrm{Br}_{5}\right) \leq 8$.

There are many problems related to irregular labeling. Therefore, we provide the following problems.

Problem 9. What is the irregularity strength of diamond graph $\mathrm{Br}_{\mathrm{n}}$ for $\mathrm{n} \geq 6$ ?

Problem 10. What is the total edge irregularity strength of diamond graph $\mathrm{Br}_{\mathrm{n}}$ for $\mathrm{n} \geq 6$ ?

Problem 11. What is the total vertex irregularity strength of diamond graph $\mathrm{Br}_{\mathrm{n}}$ for $\mathrm{n} \geq 6$ ?

Problem 12. What is the total irregularity strength of diamond graph $\mathrm{Br}_{\mathrm{n}}$ for $\mathrm{n} \geq 6$ ?

\section{ACKNOWLEDGEMENT}

This research was funded by Penelitian Dasar grant from Direktorat Penelitian dan Pengabdian Kepada Masyarakat, Kementerian Pendidikan dan Kebudayaan, Republik Indonesia, 2021.

\section{REFERENCES}

[1] Ahmad, Nurdin, \& E. T. Baskoro, E. T., 2015. On Total Irregularity Strength of Generalized Halin Graph. Ars Combinatoria, Vol. 122, pp. 319 - 332.

[2] Aigner, M. and Triesch, E., 1990. Irregular assignments of trees and forests. SIAM Journal Discrete Mathematics, Vol. 3, pp. 439 - 449.

[3] Bača, M., Jendrol,S., Miller, M., and Ryan, J., 2007. On Irregular Total Labelling. Discrete Mathematics, Vol. 307, pp. 1378 - 1388.

[4] Chartrand, G., Jacobson, M. S. , Lehel, J. , Oellermann, O. R., Ruiz, S. and Saba, F., 1988. Irregular Networks. Congressus Numerantium, Vol. 64, pp. $197-210$.

[5] Faudree, R. J. and Lehel, J., 1987. Bound on the irregularity strength of regular graphs, in Combinatorics. Colloq. Math. Soc. János Bolyai 52, North Holland, Amsterdam, pp. 247 256.

[6] Gallian, J.A., 2019. Graph labeling. Electron. J. Combin. Vol. 17, (Dynamic Survey DS\#6).

[7] Marzuki, Salman, A. N. M. , and Miller, M. ., 2013. On the Total Irregularity Strength of Cycle and Path. Far East Journal of Mathematics and Science, Vol. 8, No. 21, pp. 1- 21.

[8] Nurdin, Baskoro, E.T., Salman, A.N.M., Gaos, N.N., 2010. On the Total Vertex Irregularity Strength of Trees. Discrete Mathematics, Vol. 310, No. 21, pp. 3043 - 3048.

[9] Nurdin, Kim, H,K.,2019. Irregular Labeling on Transportation Network of Splitting graphs of stars. Proceedings of the Jangjeon Mathematical Society, Vol. 22, No. 1, pp. $103-108$.

[10] Nurdin, Zakir, M., Firman, 2013. Vertex-irregular labeling and vertex-irregular total labeling on caterpillar graph. International Journal of Applied Mathematics and Statistics, Vol. 40, No. 10, pp. 99-105.

[11] Ramdani, R. and Salman, A. N. M. ,2013. 2013. On The Total Irregularity Strength of Some Cartesian Product Graphs. AKCE International Journal of Graphs and Combinatorics, Vol. 10, No. 2, pp. $199-209$. 


\section{Jurnal Matematika, Statistika \& Komputasi}

\section{Ali Ahmad, Nurdin Hinding, Jusmawati Massalesse}

[12] Sedlàček, J., 1963. Problem 27 in Theory Graphs and Its Applications. Proceedings of the Symposiu Smolenice, pp. 163 - 167.

[13] Shulhany, M.A. and Salman, A. N. M., 2015. Bilangan Terhubung Pelangi Graf Berlian. Prosiding Seminar Nasional Matematika dan Pendidikan Matematika UMS, Vol. 11, pp. 916 $-924$.

[14] Siddiqui, M.K., Nurdin, and Baskoro, E.T. 2013. Total edge irregularity strength of the disjoint union of helm graphs. Journal of Mathematical and Fundamental Sciences, Vol. 45, No. 2, pp. 163-171.

[15] Wijaya, K. and Slamin,2008. Total Vertex Irregular Labellings of Wheels, Fans, Suns, and Friendship Graphs. Journal of Combinatorial Mathematics and Combinatorial Computing, Vol. 56, pp. $103-112$. 